\title{
MODEL PENGENALAN TERBAIK \\ DENGAN TREE-AUGMENTED NETWORK (TAN) \\ DAN ESTIMATOR MAXIMUM LIKELIHOOD (ML) \\ BERDASARKAN FITUR OBJEK
}

\author{
Irwan Budi Santoso \\ Jurusan Teknik Informatika, Sains dan Teknologi \\ Universitas Islam Negeri (UIN) Maulana Malik Ibrahim Malang \\ irwan.budi331177@gmail.com
}

\begin{abstract}
Abstrak-Pengenalan suatu objek sangat tergantung dari seberapa handal model yang digunakan serta parameter model tersebut. Tree-Augmented Network (TAN) adalah salah satu model yang handal dalam melakukan klasifikasi, yang dibangun dengan memperhatikan hubungan diantara pasangan fitur-fitur objek. Sedangkan Maximum Likellihood (ML) adalah salah satu estimator yang telah banyak digunakan dan telah teruji penggunaannya. Kehandalan model serta estimator yang digunakan pada kenyataan belum cukup untuk menghasilkan model pengenalan terbaik, akan tetapi ada faktor lain yang memberi kontribusi besar yaitu dimensi atau fitur objek yang digunakan dalam membangun model tersebut. Hasil eksperimen untuk data training yang terdiri dari 5 jenis objek ringan menunjukkan untuk dimensi objek 5x5 (25 fitur), 6x6 (36 fitur) dan 7x6 (42 fitur) menghasilkan model TAN terbaik karena memberikan tingkat akurasi sistem 100\%, sedangkan untuk dimensi dibawah atau diatas tersebut menghasilkan tingkat akurasi sistem yang lebih rendah. Kondisi tersebut menunjukkan bahwa tidak selamanya semakin besar dimensi atau fitur objek yang digunakan dalam training akan menghasilkan model yang semakin baik, karena bisa jadi semakin besar dimensi atau fitur objek akan menghasilkan informasi overflow.
\end{abstract}

Kata Kunci : Tree-Augmented Network, Maximum Likelihood, Dimensi (fitur) objek

\section{PENDAHULUAN}

Akurasi dalam mengenali suatu objek sangat tergantung dari seberapa handal model yang digunakan dalam pengenalan serta estimator yang digunakan untuk membangun dan mengestimasi parameter model tersebut. Tree-Augmented Network (TAN) adalah salah satu model yang handal dalam melakukan klasifikasi, karena secara konsep model tersebut dibangun dengan memperhatikan hubungan atau dependensi diantara pasangan fitur-fitur objek (Irwan, 2007, 2011, 2012). Sedangkan Maximum Likelihood (ML) adalah salah satu estimator yang telah banyak digunakan

dan telah teruji penggunaannya dalam banyak aspek (Duda,1973).Secara teori dalam mengenali suatu objek tidak boleh lepas dari dua hal yaitu metode dalam membangun model pengenalan serta estimator model yang digunakan, akan tetapi pada kenyataannya hanya memperhatikan dua hal tersebut ternyata masih belum cukup untuk menghasilkan suatu model pengenalan terbaik yang memberikan tingkat akurasi tinggi dalam pengenalan. Faktor lain yang dimungkinkan memberi kontribusi dalam menghasilkan model terbaik adalah kondisi dari dimensi atau fitur objek (image), khususnya fitur objek untuk pembelajaran (training) dalam membangun model pengenalan. Bertolak dari dimensi atau fitur objek tersebut, muncul permasalahan bagaimana mendapat kan atau membangun model pengenalan terbaik dengan TreeAugmented Network (TAN) dan estimator 
Maximum Likelihood (ML) berdasarkan dimensi atau fitur objek training.

\section{PRINSIP}

MAXIMUM

\section{LIKELIHOOD (ML)}

Bila diketahui data sampel training $D$ yang terdiri dari $n$ sampel $x_{1}, x_{2}, \ldots, x_{n}$ dengan asumsi identik, indenpenden distribusi variabel random (i.i.d), dapat ditentukan fungsi likelihood $p(D \mid \theta)=\prod_{k=1}^{n} p\left(x_{k} \mid \theta\right)$

dengan $\theta$ adalah parameter distribusi, maka prinsip dari estimator Maximum Likelihood (ML) untuk mendapatkan taksiran parameter $\theta$ adalah dengan memaksimumkan fungsi $p(D \mid \theta)$ (Duda,1973).

\section{BAYESIAN NETWORKS}

Bila diketahui $U=\left\{X_{1}, \ldots, X n\right\}$ adalah himpunan variabel random diskrit, maka bayesian network dinotasikan sebagai Directed Acyclic Graph (DAG) yang merupakan join distribusi probabilitas $U$. Secara formal join distribusi probabilitas tersebut merupakan sebuah pasangan Directed Acyclic Graph $(G)$ dengan parameter network $(\Theta)$ yang ditulis $B=\langle G, \Theta\rangle$. Parameter network ( $\Theta$ ) berisi suatu parameter $\theta_{x_{i} \Pi_{x_{i}}}=P_{B}\left(x_{i} \mid \Pi_{x i}\right)$ untuk setiap nilai $x_{i} \in X_{i}$ dan $\prod_{x i} \in \prod_{X_{i}}$, dimana $\prod_{X_{i}}$ merupakan sekumpulan parent dari $X_{i}$ didalam $G$. Sehingga bayesian network didefinisikan sebagai sebuah uniqe join distribusi probabilitas $U$ yang unik (Friedman,1996,1997), sebagai berikut:

$$
P_{B}\left(X_{1}, \ldots, X_{n}\right)=\prod_{i=1}^{n} P_{B}\left(X_{i} \mid \prod_{X_{i}}\right)=\prod_{i=1}^{n} \theta_{\left(X_{i} \mid \prod_{X_{i}}\right)}
$$

\subsection{Tree-Augmented Network (TAN)}

PembahasanTree-Augmented Network (TAN) berkaitan dengan naïve Bayes klasifier karena Tree-Augmented merupakan perpanjangan atau kelanjutan dari nä̈ve Bayes klasifier. Nä̈ve Bayes Klasifier diperoleh dengan pembelajaran data training $D$ yaitu dengan menentukan kodisional probabilitas pada setiap atribut $X_{i}$ bila diberikan variabel kelas $C$. Karenanya nä̈ve Bayes tidak realistis untuk diterapkan pada data riil, sehingga terdapat perbaikan pada naïve Bayes yang disebut augmented naive Bayes. Membangun augmented naive Bayes classifier equivalen dengan mencari Bayesian Network yang baik dengan variabel kelas $C$ sebagai root (Friedman,1997). Karena komputasi yang intensif maka solusi yang efisien dalam menemukan Bayesian network adalah diperbolehkannya saling mempengaruhi diantara variabel. Selanjutnya network yang dihasilkan disebut Tree-Augmented Network (TAN).

\subsection{Construct-TAN}

Construct-TAN(Amy, 2005) (Friedman, 1996, 1997) (Murphy,2001) dibangun berdasarkan prosedure Chow dan Liu dengan sedikit modifikasi. Prosedur Construct-TAN ada lima tahap, sebagai berikut:

1. Menghitung $I_{\hat{P}_{D}}\left(X_{i}, X_{j} \mid C\right)$ diantara setiap pasangan atribut, $i \neq j$.

2. Membangun graph komplit tak berarah dengan node-nya merupakan atribut $X_{1}, \ldots, X_{n}$. Sedangkan bobot pada edge $X_{i} X_{j}$ adalah $I_{\hat{P}_{D}}\left(X_{i}, X_{j} \mid C\right)$.

3. Membangun maximum weighted spanning tree (MWST) dengan algoritma Prim's (Levitin,2003).

4. Transformasi hasil dari tree tak berarah menjadi sebuah tree berarah dengan memilih sebuah root variabel dan mensetting arah edge dari root variabel tersebut.

5. Bangun model TAN dengan menambah simpul (vertex) yang diberi 
label $C$ dan menambah edge atau arc dari $C$ ke setiap $X_{i}$.

Untuk bobot $\left(I_{\hat{P}_{D}}\left(X_{i}, X_{j} \mid C\right)\right)$ diperoleh dengan menggunakan fungsi conditional mutual information, seperti pada persamaan 3 (Duda,1973) (Friedman, 1996, 1997).

$I_{P_{D}}\left(X_{i}, X_{j} \mid C\right)=\sum_{x \in X, y \in Y} P\left(X_{i}, X_{j}, c\right) \log \frac{P\left(X_{i}, X_{j} \mid c\right)}{P\left(X_{i} \mid c\right) P\left(X_{j} \mid c\right)}$

Untuk variabel kontinu, mutual information antara dua variabel kontinu dianggap sebagai joint distribution (bivariate normal) bila diberikan $C$ ( $C$ =kelas). Fungsi joint distribution $X_{i}$ dan $X_{j}$ dengan syarat $C=c$ mengikuti distribusi bivariate normal dengan mean $\mu_{i j \mid c}$ dan covariant $\sum_{i j \mid c}$ (Michael,2006). Sehingga nilai mutual information antara varaibel $X_{i}$ dan $X_{j}$ dengan syarat $C$ dapat ditentukan dengan mengacu pada persamaan 4 (Aritz,2006).

$I\left(X_{i}, X_{j} \mid C\right)=-\frac{1}{2} \sum_{c=1}^{r} P(c) \log \left(1-\rho_{c}^{2}\left(X_{i}, X_{j}\right)\right)$

adalah koefisien korelasi antara $X_{i}$ dan $X_{j}$ dengan syarat $C=c$. Adapun tahapan-tahapan dalam Construct-TAN prinsipnya sama dengan Construct-TAN untuk variabel diskret.

\subsection{Estimasi Parameter Model TAN}

Dengan mengacu pada sub-bab sebelum nya dan diasumsikan bahwa struktur model tetap maka nilai parameter $\Theta$ dapat ditentukan untuk setiap kelasnya, seperti pada persamaan 6 (Friedman, 1996,1997) (Jesus, 1999)

$$
\theta_{x_{i}\left|\Pi_{x_{i}}\right| C}=\hat{P}_{D}\left(x_{i}\left|\Pi_{x_{i}}\right| C\right)=\frac{\hat{P}_{D}\left(x_{i}, \prod_{x_{i}} \mid C\right)}{\hat{P}_{D}\left(\prod_{x_{i}} \mid C\right)}
$$

dengan $\hat{P}_{D}\left(x_{i}, \Pi_{x_{i}} \mid C\right) \approx N\left(\mu_{X_{J} \Pi_{x_{I}} \mid C}, \Sigma_{X_{J} \Pi_{X_{I}} \mid C}\right)$ dan $\hat{P}_{D}\left(\Pi_{x_{i}} \mid C\right) \approx N\left(\mu_{\Pi_{X_{x}} \mid C}, \Sigma_{\Pi_{x_{t}} \mid C}\right)$.

\section{METODE PENELITIAN}

\subsection{Construct-TAN dengan ML}

Langkah-langkah membangun Model TAN dengan menggunakan RLME untuk pengenalan suatu objek citra/image dapat dilihat secara detail pada Algoritma Membangun Model TAN dengan ML.

Algoritma Membangun Model TAN dengan Maximum Likelihood (ML)

$$
\begin{aligned}
& \text { Construct }-T A N(D) \\
& \text { for setiap } X_{i}, X_{j} \text { do } \\
& \text { Tentukan } w_{i j} \text { (bobot) } \\
& \left\{{ }^{w_{i j}}={ }^{I\left(X_{i}, X_{j} \mid C\right) \quad \text { berdasarkan parameter }}\right. \\
& \left.\sum_{i j \mid c} \text { yang diperoleh dengan } M L\right\}
\end{aligned}
$$

$U G \leftarrow$ BangunGraphTakBerard (w)

$G \leftarrow M W S T(U G)$

\{maximum weighted spanning tree\}

$$
T \leftarrow \text { BangunGraphBerarah }(G, \text { root })
$$

$T A N \leftarrow$ TambahKelas $(T)$

return TAN

Prosedur Construct-TAN adalah prosedur yang digunakan dalam learning TAN dan mengacu pada persamaan 6 dalam menentukan parameter atau bobot model.

\subsection{Eksperimen}

Untuk mendapatkan model pengenalan TAN terbaik terhadap objek tertentu dengan bantuan estimator ML untuk menghitung parameter modelnya, dicoba melakukan beberapa training terhadap data dengan objek sama, dan dimensi atau fitur 
objek yang berbeda-beda. Hasil training terhadap objek training yang sama dengan dimensi atau fitur objek yang berbedabeda kemudian dibandingkan tingkat akurasi sistemnya dalam pengenalan.

Data yang digunakan dalam eksperimen adalah data nyata dalam bentuk image yang terdiri dari 5 kelas (objek) yaitu buah apel, boneka, tekstur tanah, kaleng, dan sepatu seperti pada Gambar 1. yang masing-masing kelas memiliki sampel berukuran 15 pengamatan (Irwan, 2007).
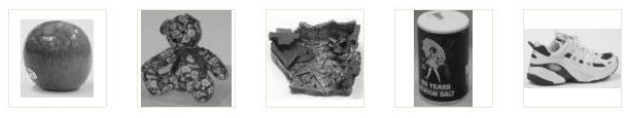

Gambar 1. Data nyata dengan lima jenis objek (buah apel, boneka, tekstur tanah, kaleng, dan sepatu)

Sedang skenario data percobaannya dapat dilihat pada Tabel 1 yaitu skenario data percobaan dengan beberapa dimensi atau fitur objek.

Tabel 1. Skenario data percobaan dengan beberapa dimensi atau fitur objek.

\begin{tabular}{|l|l|l|}
\hline Percobaan & $\begin{array}{l}\text { Dimensi } \\
\text { Objek }\end{array}$ & $\begin{array}{l}\text { Ukuran } \\
\text { Fitur }\end{array}$ \\
\hline 1 & $2 \times 2$ & 4 \\
\hline 2 & $3 \times 2$ & 6 \\
\hline 3 & $3 \times 3$ & 9 \\
\hline 4 & $4 \times 3$ & 12 \\
\hline 5 & $4 \times 4$ & 16 \\
\hline 6 & $5 \times 4$ & 20 \\
\hline 7 & $5 \times 5$ & 25 \\
\hline 8 & $6 \times 5$ & 30 \\
\hline 9 & $6 \times 6$ & 36 \\
\hline 10 & $7 \times 6$ & 42 \\
\hline 11 & $7 \times 7$ & 49 \\
\hline 12 & $8 \times 7$ & 56 \\
\hline 13 & $8 \times 8$ & 64 \\
\hline 14 & $9 \times 8$ & 72 \\
\hline 15 & $9 \times 9$ & 81 \\
\hline 16 & $10 \times 9$ & 90 \\
\hline 17 & $10 \times 10$ & 100 \\
\hline
\end{tabular}

Maksud dimensi atau fitur objek pada setiap percobaan pada Tabel 1 adalah lima jenis objek (buah apel, boneka, tekstur tanah, kaleng, dan sepatu) dalam bentuk image dengan setiap percobaan ukuran dimensi atau fiturnya sama. Sebagai misal percobaan pertama dimensi objek $2 \times 2$ atau dengan 4 fitur, maka dimensi image untuk lima jenis objek tersebut dibuat sama dengan ukuran 2x2 atau sebanyak 4 fitur.

\subsection{Pelaksanaan Eksperimen}

Pelaksanaan eksperimen (uji coba) terhadap data nyata yang meliputi lima jenis objek atau kelas dalam bentuk image, dilakukan dengan skenario data percobaan pada Tabel 1. Sedangkan pelaksanaan eksperimen dengan menggunakan data skenario tersebut dapat dilihat langkahlangkanya secara lengkap pada Gambar 2. Pelaksanaan Eksperimen.

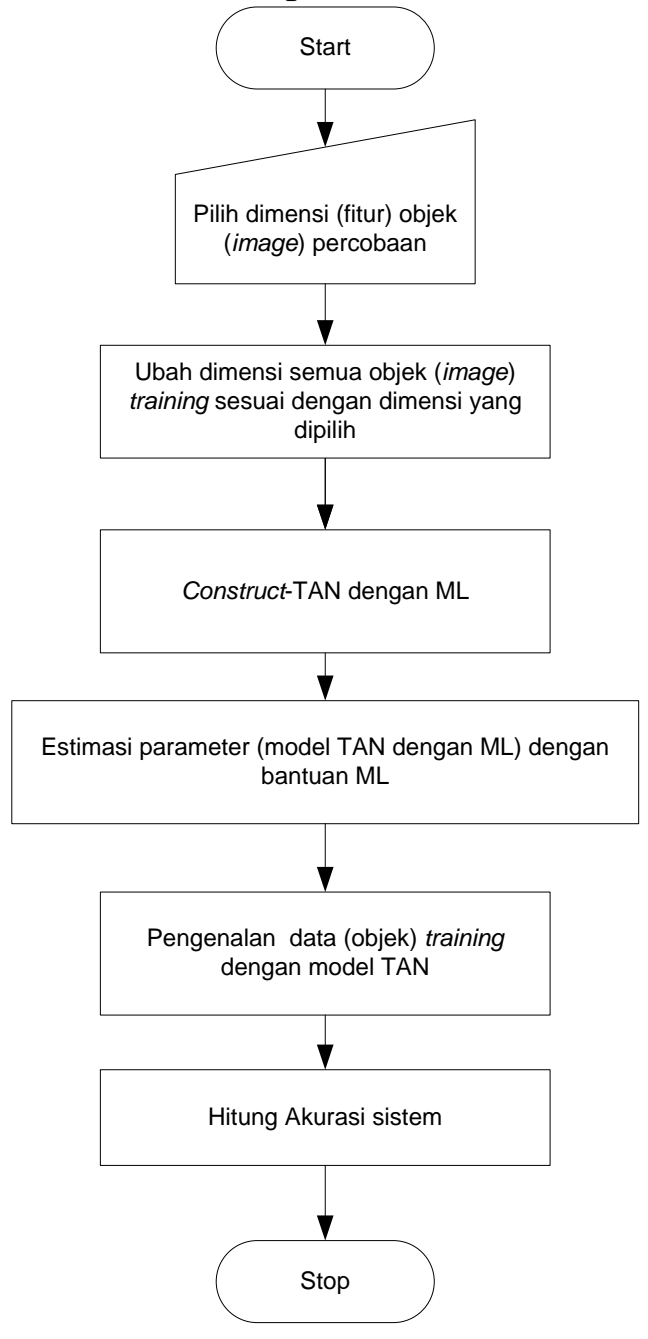

Gambar 2. Pelaksanaan Eksperimen 
Pada langkah pertama, setiap percobaan pada Tabel 1, dengan dimensi objek atau fitur yang berbeda-beda akan dibangun model TAN dengan bantuan estimator ML. Kemudian dilakukan estimasi parameter model TAN dengan bantuan estimator ML juga. Setelah dihasilkan model TAN beserta parameter modelnya, langkah berikutnya adalah melakukan pengenalan objek training dan menghitung akurasi sistem. Dari hasil perhitungan akurasi sistem pada setiap percobaan, selanjutnya dipilih model TAN dengan tingkat akurasi sistem tertinggi yang kemudian dianggap sebagai model terbaik dalam pengenalan.

\section{HASIL DAN PEMBAHASAN}

Hasil percobaan dengan menggunakan skenario data pada Tabel 1, selengkapnya dapat dilihat pada Tabel 2

Tabel 2. Tingkat Akurasi Model TAN

Dalam Mengenali Objek Training

\begin{tabular}{|l|l|l|l|}
\hline $\begin{array}{l}\text { Dimensi } \\
\text { Objek }\end{array}$ & $\begin{array}{l}\text { Ukuran } \\
\text { Fitur }\end{array}$ & $\begin{array}{l}\text { Akurasi } \\
(\%)\end{array}$ & $\begin{array}{l}\text { Kesalahan } \\
(\%)\end{array}$ \\
\hline $2 \times 2$ & 4 & 82.6667 & 17.3333 \\
\hline $3 \times 2$ & 6 & 78.6667 & 21.3333 \\
\hline $3 \times 3$ & 9 & 96 & 4 \\
\hline $4 \times 3$ & 12 & 98.6667 & 1.3333 \\
\hline $4 \times 4$ & 16 & 98.6667 & 1.3333 \\
\hline $5 \times 4$ & 20 & 98.6667 & 1.3333 \\
\hline $5 \times 5$ & 25 & 100 & 0 \\
\hline $6 \times 5$ & 30 & 98.6667 & 1.3333 \\
\hline $6 \times 6$ & 36 & 100 & 0 \\
\hline $7 \times 6$ & 42 & 100 & 0 \\
\hline $7 \times 7$ & 49 & 98.6667 & 1.3333 \\
\hline $8 \times 7$ & 56 & 97.3333 & 2.6667 \\
\hline $8 \times 8$ & 64 & 97.3333 & 2.6667 \\
\hline $9 \times 8$ & 72 & 94.6667 & 5.3333 \\
\hline $9 \times 9$ & 81 & 77.3333 & 22.6667 \\
\hline $10 \times 9$ & 90 & 58.6667 & 41.3333 \\
\hline $10 \times 10$ & 100 & 61.3333 & 38.6667 \\
\hline
\end{tabular}

Model TAN hasil training dari beberapa dimensi atau fitur objek (image), memperlihat kan bahwa untuk dimensi atau fitur yang kecil tingkat akurasi sistem model TAN dalam melakukan pengenalan relatif lebih rendah. Rendahnya tingkat akurasi sistem dibandingkan dengan yang lainnya, ditunjuk kan oleh dimensi objek 2x2 (4 fitur) sebesar 82, 6667\%, dimensi $3 \times 2$ (6 fitur) 78,6667\% . Demikian halnya untuk dimensi atau fitur yang besar, model TAN yang dihasilkkan memberikan tingkat akurasi sistem juga relatif lebih rendah dibandingkan lainnya. Rendahnya tingkat akurasi tersebut ditunjukkan pada dimensi 9x9 (81 fitur) sebesar 77,3333\%, dimensi 10x9 (90 fitur) sebesar 58,6667\% dan dimensi 10x10 (100 fitur) sebesar $61,3333 \%$.

Tingkat akurasi paling tinggi dari eksperimen, dihasilkan oleh model TAN pada dimensi $5 \times 5$ (25 fitur), dimensi 6x6 (36 fitur) dan 7x6(42 fitur) masing-masing dengan tingkat akurasi $100 \%$. Hasil ini menunjukkan bahwa pada dimensi tersebut model TAN yang dihasilkan merupakan model pengenalan terbaik. Hal penting lain yang dapat diambil dari hasil eksperimen tersebut adalah semakin kecil dimensi atau semakin besar dimensi objek yang digunakan akan berdampak model TAN yang dihasilkan semakin kurang baik. Kurang baiknya model TAN pada dimensi atau fitur objek yang semakin kecil bisa jadi karena semakin kecil dimensi atau fitur banyak informasi penting dari objek yang hilang. Sedangkan kurang baiknya model TAN yang dihasilkan pada dimensi yang semakin besar karena semakin besar dimensi atau fitur objek menyebabkan terjadinya informasi overflow.

\section{KESIMPULAN}

Kehandalan model serta estimator yang digunakan pada kenyataan belum cukup untuk menghasilkan model pengenalan terbaik, akan tetapi ada faktor lain yang member kontribusi besar yaitu kondisi dari dimensi atau fitur objek yang digunakan dalam membangun model tersebut. Hasil eksperimen menunjukkan untuk dimensi atau fitur objek semakin kecil atau untuk dimensi atau fitur objek yang semakin 
besar menghasilkan model TAN dengan tingkat akurasi sistemnya relatif lebih rendah. Kondisi tersebut menunjukkan pada dimensi atau fitur yang semakin kecil banyak informasi penting yang hilang, begitu pula semakin besar dimensi atau fitur objek yang digunakan akan menyebabkan informasi overflow sehingga menghasilkan model pengenalan yang kurang baik.

\section{REFERENSI}

1. Amy Ratnakaran, "Bayesian Network", Applied Statistics Honours, Department of Mathematics and Statistics, University of Melbourne, 2005.

2. Aritz $\mathrm{P}^{\prime}$ erez, Pedro Larra naga, and Innaki Inza, "Supervised classification with conditional Gaussian networks: Increasing the structure complexity from naive bayes", International Journal of Approximate Reasoning, vol.43.no.1, hal 1-25, 2006

3. R. Duda dan P. Hart, "Pattern Classification and Scene Analysis", John Wiley and Sons, Inc., New-York, USA, 1973.

4. Friedman, N. and Goldszmidt, M, "Building Classifiers Using Bayesian Networks", Thirteenth National Conference on Artificial Intelligence, 1996.

5. Friedman, N. D. Geiger, and M. Goldszmidt, "Bayesian network classifiers", Machine Learning, vol.29, hal 131-163, 1997.

6. Irwan B.S., "Pengenalan Objek dengan

7. Regularized Latent Maximum Entropy (RLME) dan TreeAugmented Network (TAN)", Master Tesis, Institut Teknologi Sepuluh Nopember Surabaya. 2007

8. Irwan B.S., "Pengenalan Objek dengan

15. Michael P. Ashley-Rollman, Lucia Castellanos P'erez-Bolde, "TAN
9. RLME dan TAN (Perbandingan RLME_ML dan ML_ML)", Makalah Seminar Nasional Pascasarjana VII, Institut Teknologi Sepuluh Nopember Surabaya. 2007

10. Irwan B.S, "Perbandingan Metode RLME dan ML Dalam Membangun Model TAN Untuk Mengenali Objek Dengan Fitur Berdistribusi Normal", MATICS (jurnal Ilmu Komputer dan Teknologi Informasi UIN Malang), vol.4. no.4, hal 148-154, September 2011.

11. Irwan B.S., "Perbandingan Struktur Model

12. TAN dengan Estimator RLME Dan ML Untuk Mengenali Objek Dengan Fitur Berdistribusi Normal (Studi Kasus Data Sintesis)", Prosiding Seminar Nasional SciETec Program Magister dan Doktor Fakultas Teknik, Universitas Brawijaya, 2012.

13. Jesus Cerquides, “ Applying General Bayesian Techniques to Improve TAN Induction", UBS AG Bahnhofstrasse 45, 1999.

14. Levitin, "Introduction The Design \& Analysis of Algorithms", Villanova University, 2003. 

